\title{
Elevated Lipoprotein(A) in Children and Adolescents: Early Identification is Key for Successful Intervention
}

\author{
Sergio Emanuel Kaiser ${ }^{(0}$ \\ Universidade do Estado do Rio de Janeiro, Rio de Janeiro, RJ - Brazil. \\ Editorial referring to the article: Lipoprotein(a) levels in children and adolescents: Ouro Preto Study
}

Over the last decades, numerous studies have demonstrated that elevated lipoprotein $(\mathrm{Lp})(\mathrm{a})$ is a powerful and independent risk factor for coronary heart disease, ${ }^{1,2}$ ischemic stroke, ${ }^{3}$ and calcific aortic stenosis. ${ }^{4}$ Even in patients treated with statins who achieve LDLcholesterol goals below $70 \mathrm{mg} / \mathrm{dL}$, elevated Lp(a) levels remain independently related to an increased risk of atherosclerotic events. ${ }^{5}$

The LDL particle has a unique molecular structure, as exemplified by its covalent bond with an apolipoprotein(a) that bears resemblance to plasminogen and may well represent an evolutionary deviation of this well-known plasmin precursor. ${ }^{6} \mathrm{Lp}(\mathrm{a})$ is synthesized by the liver and the amount of circulating particles in the bloodstream is almost exclusively determined by inheritance, leaving very little space for environmental influence. The distribution of Lp(a) levels in the population is highly skewed with approximately $80 \%$ of people exhibiting plasma concentrations below $50 \mathrm{mg} / \mathrm{dL}$, and the remaining $20 \%$ with a wide range of values above that limit.

Despite its unequivocal importance as a cardiovascular risk factor, until recently there had been little interest in aggregating its measurement to the lipid profile determination, and this underappreciation has been reflected even in recent lipid guidelines ${ }^{7-9}$ : Lp(a) measurement is recommended, as stated by the aforementioned guidelines, for patients who have experienced an atherosclerotic event unexplained

\section{Keywords}

Lipoprotein(a); Atherosclerosis; Child; Adolescents; Coronary Artery Diseases; Statins/therapeutic, use; Aortic Stenosis. by traditional risk factors, for those with familial hypercholesterolemia and for people who either suffered a premature heart attack, or have a family history of premature atherosclerotic cardiovascular disease. Possible explanations for the gap between epidemiological and genetic evidence and the incorporation of $L p(a)$ measurement in clinical practice may involve (1) the lack of standardization of its unit (nMol/L or $\mathrm{mg} / \mathrm{dL})$; (2) the use of immunoassays based on non-specific antibodies targeted at more than one copy of the kringle-IV2 subtype on the same Apo(a) particle; (3) disagreement about cutoff points to define increased risk and; (4) a perception among the medical community that no therapeutic solution is yet available.

With the publication of a dose-escalating study that assessed the efficacy and safety of an antisense oligonucleotide capable of silencing the messenger RNA responsible for $\mathrm{Apo}(\mathrm{a})$ translation, ${ }^{10}$ there has been an ever growing interest in the identification of patients who might be candidates for this new therapy, which is currently being studied in a multicenter double-blind randomized outcome study. ${ }^{11}$ In 2019, possibly as an acknowledgement of the potential advantage of emerging pharmacological approaches, the European Society of Cardiology prompted to recommend the measurement of $L p(a)$ at least once in a lifetime, irrespective of the presence of other risk factors. ${ }^{12}$

The Apo(a) gene is fully expressed by the fifth year of life, when plasma levels similar to those observed in adulthood can be reached. ${ }^{13,14}$ In children and adolescents, elevated $L p(a)$ has been reported to be associated with a positive family history of premature cardiovascular disease and early predictors of atherosclerosis such as endothelial dysfunction. ${ }^{15}$ 
In a previous cross-sectional study carried out in a sample of adults living in Ouro Preto, Minas Gerais, Cândido et al. found an independent relationship of elevated Lp(a) levels with the Framingham risk score and ischemic heart disease. ${ }^{16}$ In the present issue of the IJCS, the authors extend their observations on the association of elevated Lp(a) with risk factors to a cohort of 320 school children between 6 and 14 years old from the same town. ${ }^{17}$ It is noteworthy that the assay, as stated by the authors, was highly specific for lipoprotein(a) and minimized the interference introduced by heterogeneity in apo(a) isoforms. With a careful definition and assessment of laboratory and anthropometric variables and, as much as possible, with the incorporation of parental variables, the authors explored the possible association of the risk factors with Lp(a) levels. Among schoolchildren, no independent association of $\mathrm{Lp}(\mathrm{a})$ with traditional risk factors was found after adjustments by multivariate analysis, but body adiposity and maternal systolic blood pressure seemed to have an influence on the concentration of that lipoprotein. In contrast to studies carried out in racially segregated populations, the authors did not find any influence of skin color on Lp(a) levels, an information that matches with the highly miscigenated character of our population.

As acknowledged by the authors, the statistical significance of some associations might be hampered by the small number of cases in some of the subgroups. This is evident in Table 5, where body adiposity above reference values, clustered with increased maternal systolic blood pressure, yielded a marginal but not statistically significant association with higher Lp(a) concentrations. Conversely, raised maternal blood pressure clustered with body adiposity within reference values had a strong significant association with high $\mathrm{Lp}$ (a) values. In the first case, there were only 10 subjects with $\mathrm{Lp}(\mathrm{a})$ below $25.5 \mathrm{mg} / \mathrm{dL}$ and 15 above this value, raising the possibility of play of chance.

Another source of uncertainty may be the method chosen to assess body adiposity. Although dual-energy X-ray absorptiometry (DXA) is the gold standard method, it is hardly feasible in routine clinical practice, as opposed to bioelectrical impedance analysis. However, some authors cast doubts on the agreement of results between both methods, ${ }^{18,19}$ especially at individual level, ${ }^{19}$ which could leave room for some degree of inaccuracy in body composition measurement.

A question not addressed by the authors, as it was not the scope of the research, pertains to the ideal age to measure Lp(a) levels. Obesity epidemic has hit hard emerging countries and there is an alarming rate of increase in overweight and obesity amongst children and adolescents. ${ }^{20}$ If timely assessed, an elevated Lp(a) should be a strong reason to emphasize the promotion of a healthy lifestyle. Therefore, screening for $\mathrm{Lp}(\mathrm{a})$ might target not only children with a positive family history of premature atherosclerotic disease or raised Lp(a), but also, as suggested by the present article, obese and overweight children born from parents with multiple risk factors, especially in the presence of maternal hypertension.

\section{References}

1. The Emerging Risk Factors Collaboration, Erqou S, Kaptoge S, Perry PL, Angelantonio E, Thompson A, et al. Lipoprotein(a) concentration and the risk of coronary heart disease, stroke, and nonvascular mortality. JAMA. 2009;302(4):412-23.

2. Kamstrup PR, Benn M, Tybjærg-Hansen A, Nordestgaard BG. Extreme lipoprotein(a) levels and risk of myocardial infarction in the general population. Circulation. 2008;117(2):176-84.

3. Nave AH, Lange KS, Leonards CO, Siegerink B, Doehner W, Landmesser $\mathrm{U}$, et al. Lipoprotein (a) as a risk factor for ischemic stroke: a metaanalysis. Atherosclerosis. 2015;242(2):496-503.

4. Thanassoulis G, Campbell CY, Owens DS, Smith JG, Smith AV, Peloso GM, et al. Genetic associations with valvular calcification and aortic stenosis. N Engl J Med. 2013;368(6):503-12.

5. Albers JJ, Slee A, O’Brien KD, Robinson JG, Kashyap ML, Kwiterovich PO, et al. Relationship of apolipoproteins A-1 and B, and lipoprotein(a) to cardiovascular outcomes: the AIM-HIGH trial (Atherothrombosis Intervention in Metabolic Syndrome With Low HDL/High Triglyceride and Impact on Global Health Outcomes). J Am Coll Cardiol. 2013;62(17):1575-9.

6. Tsimikas S. A test in context: lipoprotein(a): diagnosis, prognosis, controversies, and emerging therapies. J Am Coll Cardiol. 2017;69(6):692-711.

7. Anderson TJ, Grégoire J, Pearson GP, Barry AR, Couture P, Dawes M, et al. 2016 Canadian Cardiovascular Society Guidelines for the management of dyslipidemia for the prevention of cardiovascular disease in the adult. Can J Cardiol. 2016;32(11):1263-82.

8. Faludi AA, Izar MCO, Saraiva JFK, Chacra APM, Bianco HT, Afiune Neto A, et al. Atualização da Diretriz Brasileira de Dislipidemias e Prevenção da Aterosclerose - 2017. Arq Bras Cardiol. 2017;109(1):1-76.

9. Grundy SM, Stone NJ, Bailey AL, Beam C, Birtcher KK, Blumenthal RS, et al. 2018 AHA/ACC/AACVPR/AAPA/ABC/ACPM/ADA/AGS/ APhA/ASPC/NLA/PCNA Guideline on the Management of Blood Cholesterol: a report of the American College of Cardiology/American Heart Association Task Force on Clinical Practice Guidelines. Circulation. 2019 June;139:e1082-1143.

10. Tsimikas S, Karwatowska-Prokopczuk E, Gouni-Berthold I, Tardif J-C, Baum SJ, Steinhagen-Thiessen E, et al. Lipoprotein(a) reduction in persons with cardiovascular disease. N Engl J Med. 2020;382(3):244-55. 
11. Novartis Pharmaceuticals. A randomized double-blind, placebocontrolled, multicenter trial assessing the impact of lipoprotein (a) lowering with TQJ230 on major cardiovascular events in patients with established cardiovascular disease [Internet]. Report No.: NCT04023552. clinicaltrials.gov; 2020. [acesso em 20 set 2020]. Disponível em: https:// clinicaltrials.gov/ct2/show/NCT04023552.

12. Mach F, Baigent C, Catapano AL, Koskinas KC, Casula M, Badimon L, et al. 2019 ESC/EAS Guidelines for the management of dyslipidaemias: lipid modification to reduce cardiovascular risk. Eur Heart J. 2020;41(1):111-88.

13. Lazarte J, Hegele RA. Pediatric dyslipidemia-beyond familial hypercholesterolemia. Can J Cardiol. 2020;36(9):1362-71.

14. Thomas NE, Davies B, Baker JS. Lipoprotein(a) in healthy Welsh schoolchildren aged 12-13 years. Arch Dis Child. 2009;94(12):998-9.

15. Lapinleimu J, Raitakari O, Lapinleimu H, Pahkala K, Rönnemaa T, Simell OG, et al. High lipoprotein(a) concentrations are associated with impaired endothelial function in children. J Pediatr. 2015;166(4):947-52.
16. Cândido APC, Ferreira S, Lima AA, Nicolato RLC, Freitas SN, Brandão $\mathrm{P}$, et al. Lipoprotein(a) as a risk factor associated with ischemic heart disease: Ouro Preto Study. Atherosclerosis. 2007;191(2):454-9.

17. Cândido APC, Mendonça-Mendes A, Cândido DRC, Nicolato RLC, Machado-Coelho GLL. Lipoprotein(a) levels in children and adolescents: Ouro Preto Study. Int J Cardiovasc Sci. 2021; 34(1):10-18.

18. Costa RF, Cyrino ES. Vertical segmental tetrapolar bioimpedance for excess body fat assessment in adolescents. J Pediatr. 2016;92(3):319-22.

19. Achamrah N, Colange G, Delay J, Rimbert A, Folope V, Petit A, et al. Comparison of body composition assessment by DXA and BIA according to the body mass index: a retrospective study on 3655 measures. PLoS One. 2018;13(7):e200465.

20. World Health Organization [Internet]. Obesity and overweight. [acesso em 21 set 2020]. Disponível em: https://www.who.int/news-room/factsheets/detail/obesity-and-overweight 